instance) of studies on the medium-term future for the various areas of physics.

The other subjects which were discussed included information channels, east-west aid and refereeing. The launching of the mobilty programme and the special programme for east and central Europe, and the start of the process leading to the next Framework programme, require improved communication with physicists via EPS channels. A budget line covering the EPS library aid programme is in principle available and a similar line may materialise in due course for the former Soviet Union and for Yugoslavia.

1993 H.-P. Europhysics Prize

If you intend to submit a nomination please inform the Secretariat by 30 June 1992.

\section{APS-EPS Meeting Defines Joint Actions}

The 20th anniversary of Hungary's bilateral cooperation with the US National Science Foundation was a fitting time for EPS and the American Physical Society to meet in Budapest to out work ways to help physics in east and central Europe (E\&CE). The meeting developed from discussions between groups in the two Societies tackling the region's difficulties. The EPS has formally established the East-West Coordination Committee (EWCC) and the APS recently appointed Irving Lerch as its Direcstrengthen international activities. $\mathrm{He}$ draws upon the International Physics Group (IPG) and Committees on International Scientific Affairs and on International Freetor of International Scientific Affairs to

\section{BERGISCHE UNIVERSITÄT- GESAMTHOCHSCHULE WUPPERTAL}

\section{The Institute for Materials Science}

invites applications for three newly-created, tenured faculty positions:

FULL PROFESSOR (Universitätsprofessor C4) of

Experimental Physics in the area of condensed matter science

ASSOCIATE PROFESSOR (Universitätsprofessor (C3) of

Applied Physics in the area of high-frequency superconductivity

ASSOCIATE PROFESSOR (Universitätsprofessor C3) of

Microstructure Technology in the are of low-pressure plasma research and applications.

Successful applicants for the physics positions will be appointed to the physics faculty. The Professor of Microstructure Technology will become a member of the Department of Electrical Engineering, and, in addition, will serve as Deputy Director of the Research Centre of Microstructure Technology. Each faculty member is expected to participate in research, teaching, and further development of the newly-formed curriculum in materials science. The full professor position is contingent upon approval of the materials science curriculum by the Senate.

Applicants must satisfy the legal requirements of the Land Nordrhein-Westfalen for the above appointment, namely Habilitation or the equivalent scientific merits or degrees. They should send their curriculum vitae, a summary of their scientific career including teaching experience and a list of publications by the 5th of October 1992 to the Director of the Institute of Materials Science, Prof. Dr. S. Dietrich, Fachbereich Physik, Bergische Universität-Gesamthochschule Wuppertal, Postfach 100127, W-5600 Wuppertal 1, Federal Republic of Germany. dom of Scientists (CISA and CIFS).

The meeting was hosted by I. Lovas, Director-General of the Central Research Institute of Physics of the Hungarian Academy of Sciences. The EWCC and the Presidents of the two Societies met separately and then together in plenary sessions in order to map out a coherent set of detailed actions and overall strategies. The latter will be articulated by the Presidents via joint letters and declarations which, as far as the E\&CE is concerned, promote a "bottomup" approach, centres of excellence, universal access to modern communication systems, and international peer review.

Priority actions are:

- To catalogue communications problems (notably in the area of electronic mail) and to develop plans for specific countries with exceptionally bad computer networks.

- To improve the distribution of information by coordinating databases (library needs, electronic communications, the status of programmes, etc.) and by launching new ones; and by combining networks, notably the EWCC, the APS database on volunteers ready to serve in $E \& C E$, and the IPG Information Net of local contacts.

- To develop mechanisms whereby APS could participate with EPS in summer schools and workshops modelled on the EPS Southern European School in Physics and based on proposals prepared by national societies and Divisions.

- To expand and consolidate existing databases on used equipment and to establish distribution mechanisms.

- To coordinate library support: the APS agreed to ship, via EPS, one complete oneyear set of all APS publications to each of the eight countries in the region and the EWCC will intensify efforts to raise funds for the library aid programme. The back issues campaign will be extended to the US. - To draw up a joint list of qualified peer reviewers and to respond to requests for reviews. The importance of peer reviews, and the Societies' willingness to help, will be stressed by distributing a joint Presidential letter to authorities in the region.

- To establish guidelines defining centres of excellence and to respond to requests to promote new centres. A preliminary step will be to complete the EWCC directory of physics institutes.

- To promote EWCC efforts to develop regionally-based graduate programmes.

- To better coordinate the announcement and planning of EPS and APS conferences. - To support E\&CE participants to the Physics Olympiad in 1993 in the US.

A number of items clearly require further consideration before discussing specific actions at the next joint meeting in Amsterdam on 2/3 October 1992. For instance, ways need to be identified to help stem the brain drain, provide training abroad while education and research is being reformed, support truly competitive peer review systems, and promote regional collaboration between groups. 